\title{
LIFE CYCLE ASSESSMENT FOR LONG-TERM Production OpERATION
}

\author{
GAKU, R. *, LUANGKESORN, L. ** \& TAKAKUWA, S. ***
}

Abstract: In this study, associative digital technologies, machine learning, and simulation are used to process both operational and related economic data from an actual poultry farm. The objective is to quickly assess and predict the inherent reliability of long-term egg production operations based on the egg production life cycle. First, a machine learning algorithm is applied to forecast egg trade prices between poultry farms and egg dealers based on historical economic data. Then, designed simulation models are applied along with collected operational data to assess the inherent reliability of historical life cycles. As a result, machine learning and simulation technological advancements are powerful and effective for associative utilization of large volumes of both related economic and operational data.

Key words: Life Cycle Assessment, Planning and Scheduling, Machine Learning, Simulation
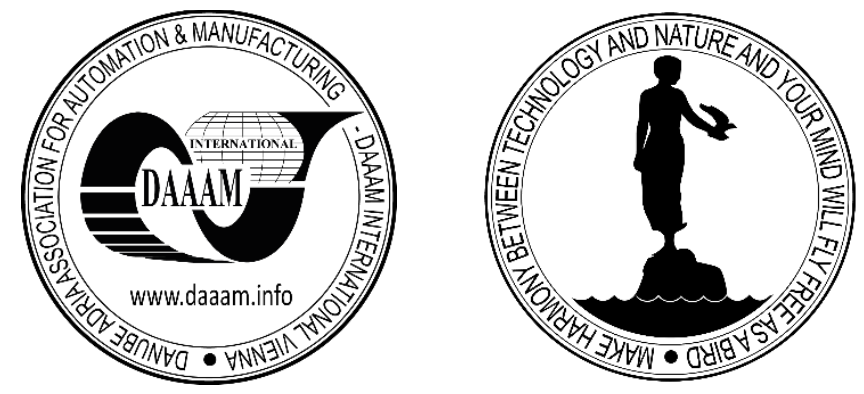

Authors' data: Prof. Dr. Gaku, R[ie]*, University of Momoyama, Faculty of Business Administration, 1-1 Manabino Izumi, Osaka, 594-1198, Japan, r-gaku@ andrew.ac.jp; Dr. Luangkesorn L[ouis]**, Highmark Health, 120 Fifth Avenue, Pittsburgh, 152223099, USA, lluangkesorn@ @itt.edu; Prof. Dr. Takakuwa, S[oemon]***, Chuo University, 742-1 Higashinakano Hachioji-shi, Tokyo, 192-0393, Japan, takakuwa@kc.chuo-u.ac.jp

This Publication has to be referred as: Gaku, R[ie]; Luangkesorn, L[ouis] \& Takakuwa, S[oemon] (2021). Life Cycle Assessment for Long-term Production Operation, Chapter 11 in DAAAM International Scientific Book 2021, pp.131-138, B. Katalinic (Ed.), Published by DAAAM International, ISBN 978-3-902734-31-0, ISSN 1726-9687, Vienna, Austria

DOI: $10.2507 /$ daaam.scibook.2021.11 


\section{Introduction}

Egg production operations typically have a life cycle of more than two years. Thus, inherent life cycle reliability has become a competitive advantage in long-term poultry production operations. Even though more operational data are collected in poultry production activities, planning and scheduling $(\mathrm{P} \& S)$ of poultry production remain a difficult task. Inherent reliability knowledge such as poultry viability and intensity must provide an asset from the operation for future long-term poultry $\mathrm{P} \& \mathrm{~S}$.

In this study, a machine learning algorithm is applied to forecast egg trade prices between poultry farms and egg dealers using related economic data such as domestic egg importing volume, sale prices, and regional poultry supply. Then, to assess the inherent reliability of historical life cycles, data-driven simulation modeling is developed and presented. The purpose is to facilitate long-term $P \& S$ of new production life cycles by forecasting profits and costs based on production cycles of layer hens. By employing the data analysis approach proposed in this study, the performance of new production life cycles can be tested using the latest collected data.

\section{Machine Learning and Simulation}

Over the past decades, an increasing number of real-time operational data have become available to be collected electronically and continually. Machine learning and simulation have both played an important role in operations management by providing unique advantages in processing and analyzing more usable business data.

Artificial intelligence (AI) is now making its way into manufacturing. Buchmeister et al. (2019) addressed an overview of the major future changes in the production branch triggered by the use of artificial intelligence. Machine learning technology and pattern-recognition software can be the key factors to transforming factories in the near future. Machine learning is commonly used for data analysis, data classification, and forecasting, and it is responsible for generating ideas for efficient $\mathrm{P} \& S$. As a result, machine learning has made it easier to analyze large volumes of business data. Thus, the combined use of both technologies is expanding the P\&S of production management. A simulation can also be used to evaluate the interactions between different resources and to optimize manufacturing systems.

P\&S activities, on the other hand, focus on how to generate an intermediate and precise plan or a schedule from computerized information, which includes complete representations of operating constraints and custom rules (Sturrock et al., 2018). In a manufacturing environment, the scheduling function must interact with other decisionmaking functions (Pinedo, 2016). Therefore, simulation is becoming a popular method for interaction of virtual and physical systems (Gaku et al., 2020). It also means that simulation needs various data sources, such as parameters and data generated by a machine learning algorithm (MLA), to enable better performance prediction of utilization areas. In other words, combining the use of both digital technologies and real-time or near real-time business data for evaluating systems, comparing alternatives, and optimizing configurations can be a smart way to support production management. 
The significant advantages and functions of machine learning and simulation for both planners and schedulers of production management in actual poultry production activities are detailed in sections 4.1 and 4.2.

\section{Life Cycle Basis of Poultry Production}

Ainan Farm, with a capital of 5 million Japanese yen is one of the largest longestablished poultry farms in Chita town, Aichi Prefecture, Japan. The poultry farm was established more than 60 years ago and has since been developed to include three chain regional poultry farms named Head, Kiriyama, and Shiofu for layer hens, as well as hatching eggs farm on the same agricultural land. Ainan Farm is mainly engaged in hen breeding for the production of consumption eggs. The company also operates a fertilizer factory that recycles fowl droppings to promote environmental conservation.

For efficient and profitable poultry operations, daily and periodical activities such as collecting and recording poultry viability, egg-laying intensity, and fodder consumption are performed. However, these records and data are unable to directly provide improved benefits of physical performance and expenses, as well as insight into the strengths and weaknesses of poultry operations. Operation managers of the poultry farms are working to develop ways to utilize their large volumes of actual business data to gain useful knowledge about the life cycle of poultry production.

Figure 1 shows the general life cycle spans of poultry production activities. As a rule, when laying hens finish the pullet phase, a laying phase starts at 112 days of age, with an egg-laying intensity of $0 \%-5 \%$. This study is based on business data provided by object-rearing farms of Japan.

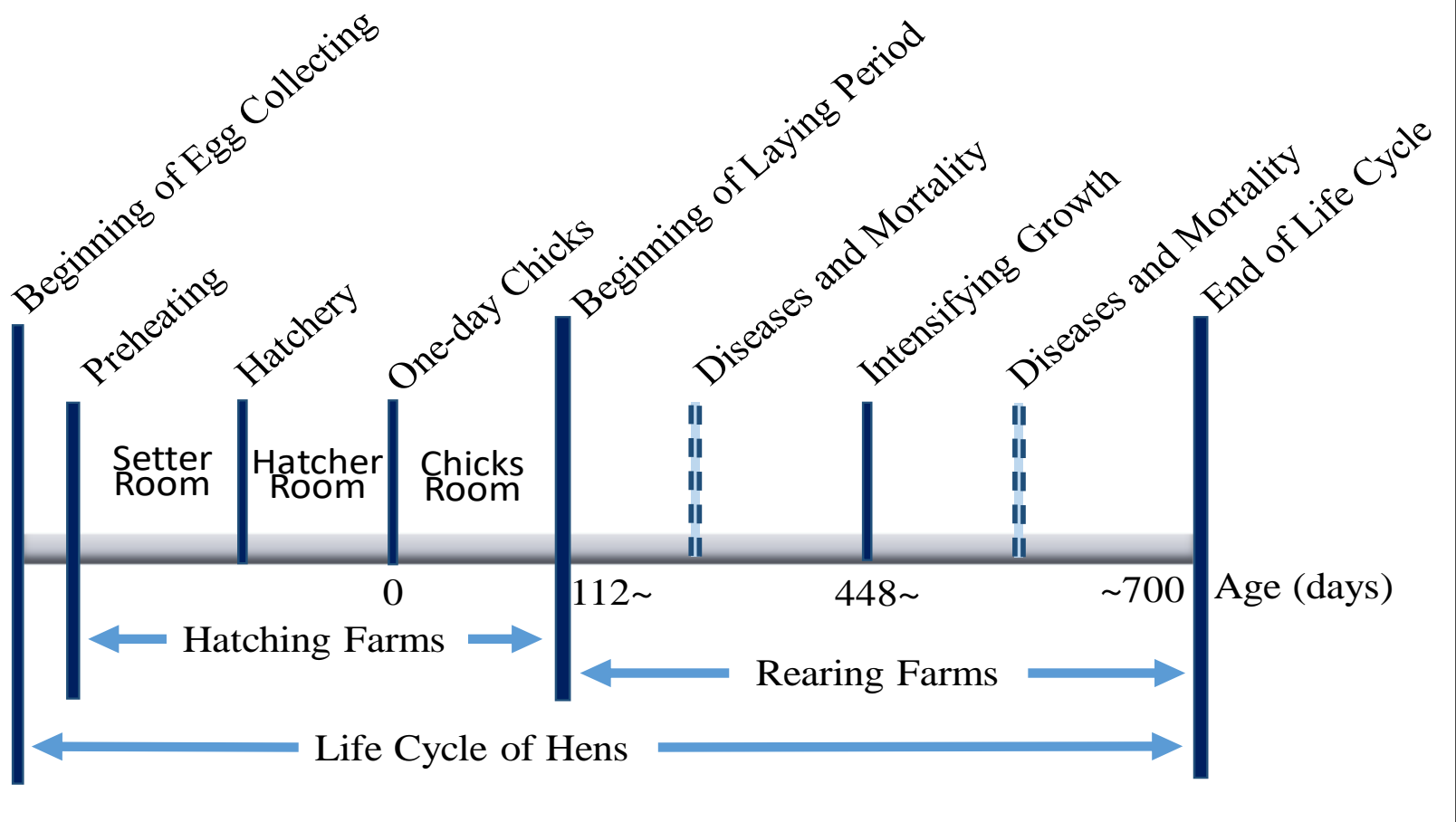

Fig. 1. Life cycle basis of poultry production 


\section{Case Study}

Life cycle assessment (LCA) has been widely used in livestock production so far (McAuliffe et al., 2016). In this study, the goal of LCA is to provide more accurate information of the production output, profit, and cost for each period in terms of business data both inside and outside Ainan Farm. Ainan's daily poultry production operation records inside real business data such as egg-laying intensity, poultry viability, and fodder consumption, as well as outside historical economic data such as egg trade prices between poultry farms and egg dealers and amount of imported foreign egg. LCA using machine learning and simulation can be applied to provide planning indicators that can help operation managers in preparing more accurate production cycle forecasts.

\subsection{Data collection}

The required data for the data analysis procedure presented in this study provides inputs to monitor and forecast production activity, including the following three categories recorded in Ainan's daily poultry production operation: (1) Egg-laying intensity; (2) Poultry viability; and (3) Fodder consumption. Figure 2 shows parts of actual observation data of egg-laying intensity and poultry viability obtained from the Head farm of Ainan. Egg-laying intensity curves have a rising phase, a plateau sector, and a downward slope. In addition to the data on egg-laying intensity and poultry viability, average daily fodder consumption data are critical in forecasting costs and profits of poultry management. Therefore, fodder consumption data are applied as the only cost factor to the data analysis procedure of this study.

A part of the actual data example used for the training dataset of the MLA is shown in Figure 3. The goal of the MLA is to develop highly accurate associative trade price variables that can power simulations to rely not only on the historical data collection inside the business, but also aggregating and incorporating the intelligence of other egg supply chains to obtain more accurate LCA information.

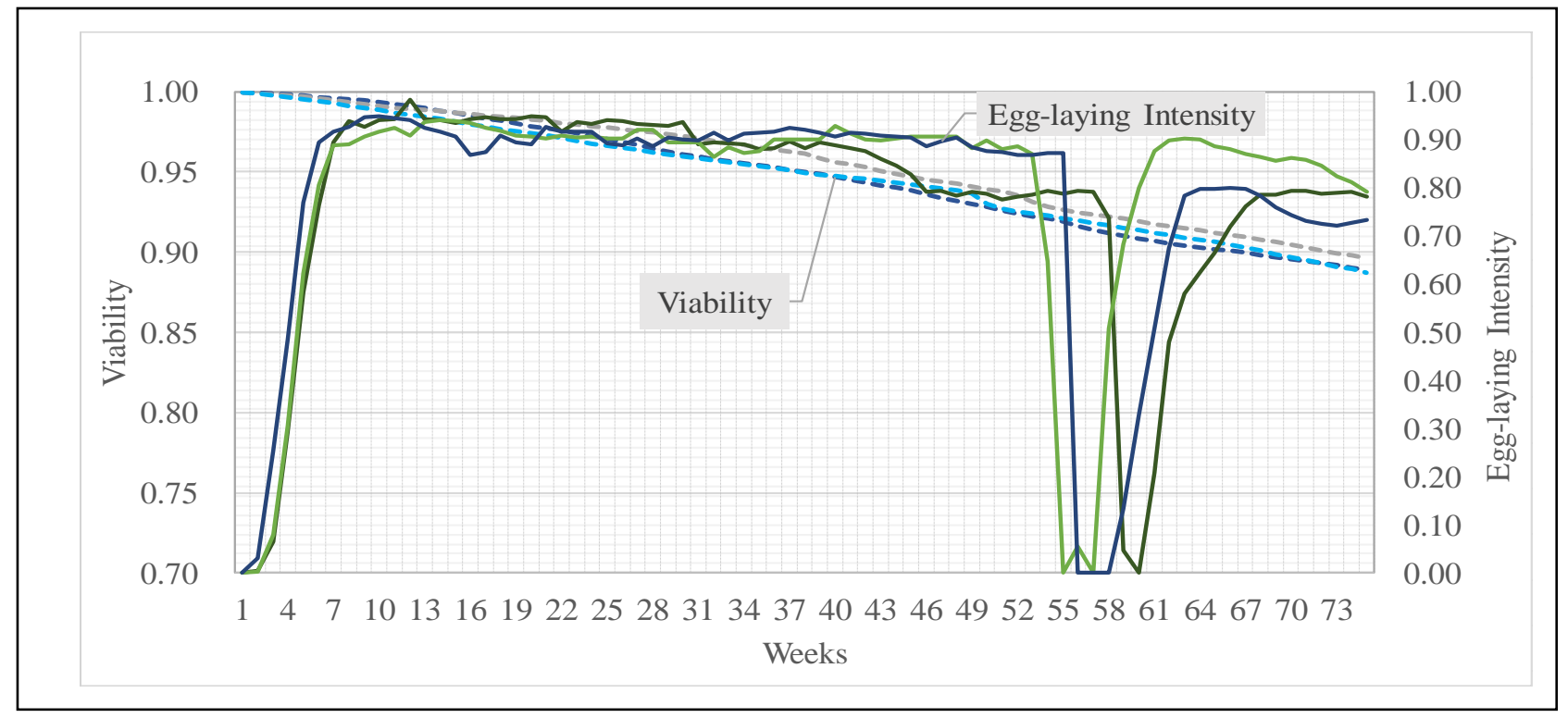

Fig. 2. Part of real operational data of egg-laying intensity and poultry viability. 


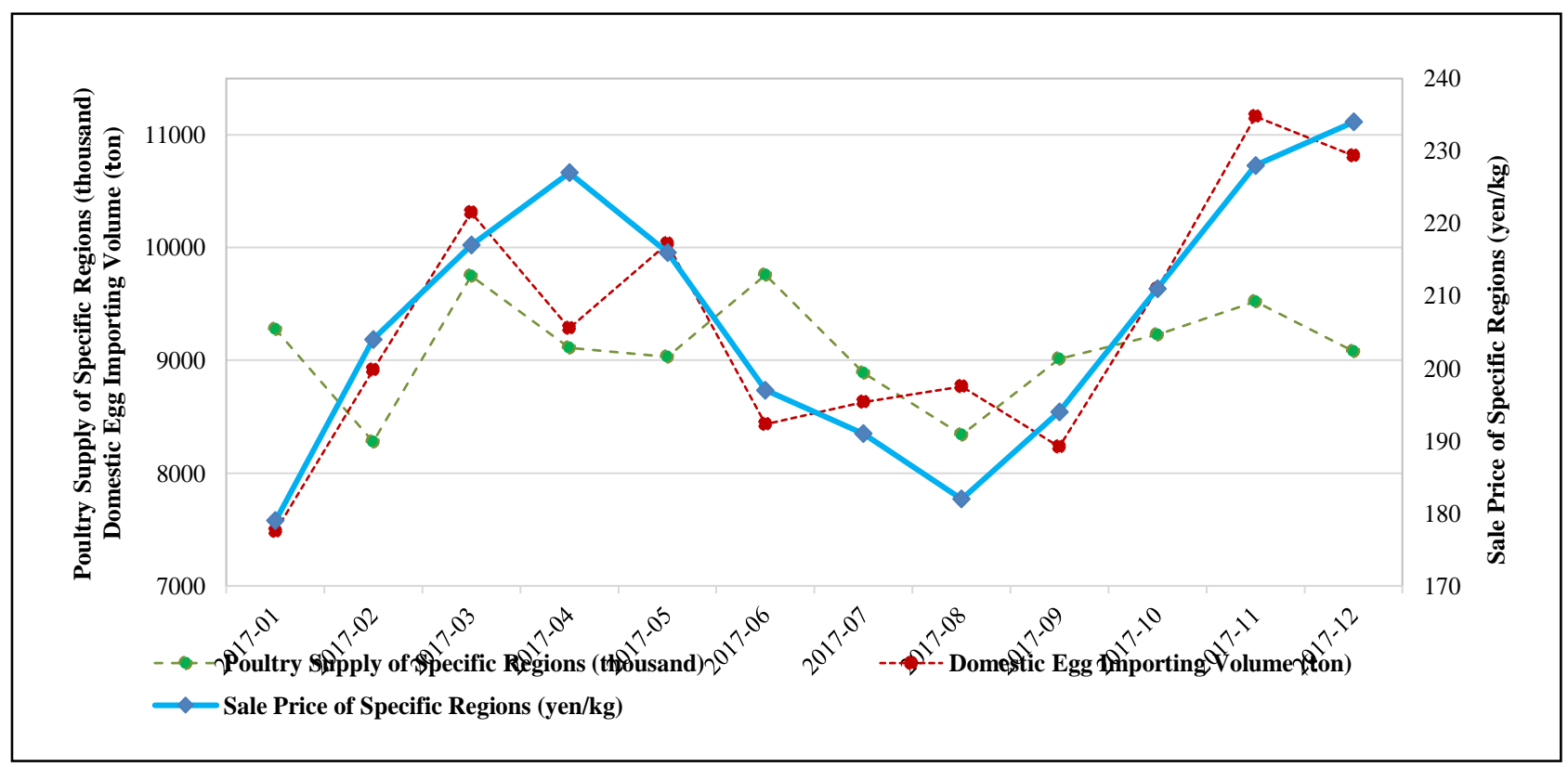

Fig. 3. Part of the training dataset example used for the machine learning algorithm.

\subsection{Approach}

The data utilization relationships between MLA and simulation modeling are shown in Figure 4. The MLA is presented to learn complex relationships from training datasets, such as historical data of egg trade prices between poultry farms and egg dealers and the number of imported foreign eggs. The trade prices forecasting results are obtained as the desired output. The results are used as input data of trade price to forecast profits over the production cycle range.

The main logic of the data analysis procedure, which uses historical data in daily poultry production operations, can be mathematically expressed as follows:

$$
\begin{aligned}
& \mathrm{O}=\mathrm{L} \times \mathrm{V} \times \mathrm{I} \\
& \mathrm{C}=\mathrm{L} \times \mathrm{V} \times \mathrm{F}
\end{aligned}
$$

where,

$\mathrm{C}=$ Average fodder cost

$\mathrm{F}=$ Fodder consumption for each hen per day

$\mathrm{I}=$ Average egg-laying intensity

$\mathrm{O}=$ Average production output

$\mathrm{L}=$ Level of poultry input

$\mathrm{V}=$ Average Poultry viability

Here, $\mathrm{O}$ is the average production output, which can provide insight for sales planning, production planning, and various operating-scheduling plans. $\mathrm{C}$ is the average fodder cost, which is useful in planning for expenditures, business expansion, and other purposes. 
Gaku, R.; Luangkesorn, L. \& Takakuwa, S.: Life Cycle Assessment for Long-term ...

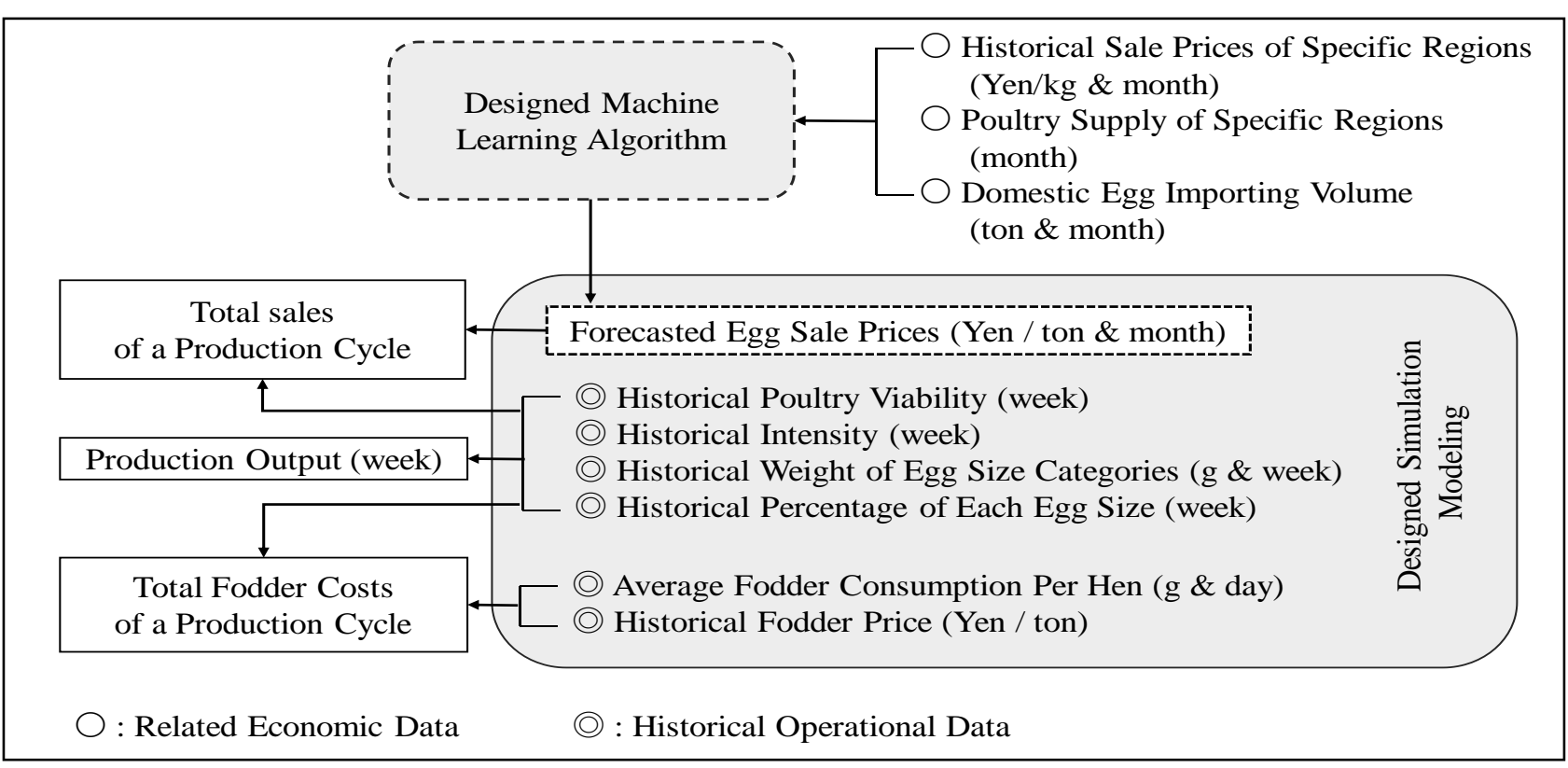

Fig. 4. Data utilization relationships between machine learning algorithms and simulation modeling.

The following is a diagram of the proposed data analysis procedure for long-term production of LCA. First, data preparation involves extracting data from actual historical business data warehouses. Data includes the historical egg-laying intensity, poultry viability, fodder consumption, and other information from decision-makers. Then, at the second step, data analysis using machine learning is responsible for providing appropriate data for the next step. For example, egg sale prices between poultry farms and egg dealers can be forecasted using linear regression models based on historical sale price data, total poultry supply in a specific Tokai region, and domestic egg importing volume.

At the third step, input data and input parameters are then prepared for use in the simulation models. Selected input data for the simulation of LCA is shown in Table 1. Furthmore, at step 4, simulation models are created to represent real poultry production operation activities. The simulation models will use input data prepared in Steps 1 through 3. At step 5, simulation results are used to make long-term operational management decisions, including average fodder costs and production output for each week, as well as estimates of total sales and costs of a production cycle. Finally, evaluation of simulation results is gathered from Step 5 to improve long-term production and operational planning, including fodder procurement, egg-marketing strategies, and financial decisions for each poultry production cycle.

\subsection{Productivity and Cost comparison}

A simulation is a powerful tool for analyzing the performance of complicated production systems, independent of how complicated relationships between actual operations data are. In this study, two relevant key performance indicators (KPIs) designed to assess the inherent reliability of historical life cycles to compare productivity and cost for each poultry production cycle are as follows:

- Egg sales for certain period based on a life cycle basis

- Fodder costs for certain period based on a life cycle basis 
(a) Historical poultry viability (week)

\begin{tabular}{|c|c|c|c|c|c|}
\hline Week 1 & Week 2 & Week 3 & $\ldots$ & Week 66 & $\ldots$ \\
\hline 0.9995 & 0.9991 & 0.9985 & $\ldots$ & 0.8354 & $\ldots$ \\
\hline 0.9996 & 0.9992 & 0.9986 & $\ldots$ & 0.9034 & $\ldots$ \\
\hline$\ldots$ & $\ldots$ & $\ldots$ & $\ldots$ & $\ldots$ & $\ldots$ \\
\hline
\end{tabular}

(b) Historical poultry intensity (week)

\begin{tabular}{|c|c|c|c|c|c|}
\hline Week1 & Week2 & Week3 & $\ldots$ & Week66 & $\ldots$ \\
\hline 0.0000 & 0.0506 & 0.3406 & $\ldots$ & 0.8178 & $\ldots$ \\
\hline 0.0006 & 0.0149 & 0.1372 & $\ldots$ & 0.7721 & $\ldots$ \\
\hline 0.0000 & 0.0310 & 0.1869 & $\ldots$ & 0.8901 & $\ldots$ \\
\hline$\ldots$ & $\ldots$ & $\ldots$ & $\ldots$ & $\ldots$ & $\ldots$ \\
\hline
\end{tabular}

(c) Historical percentage of egg sizes
\begin{tabular}{|l|c|c|c|c|c|c|c|}
\hline Egg sizes & SS & S & MS & M & L & LL & $3 L$ \\
\hline & $\ldots$ & $\ldots$ & $\ldots$ & $\ldots$ & $\ldots$ & $\ldots$ & $\ldots$ \\
\hline Week 10 & 0.0000 & 0.0018 & 0.2835 & 0.6775 & 0.0372 & 0.0000 & 0.0000 \\
\hline Week 11 & 0.0000 & 0.0018 & 0.2665 & 0.6856 & 0.0461 & 0.0000 & 0.0000 \\
\hline Week 12 & 0.0000 & 0.0014 & 0.2373 & 0.7018 & 0.0594 & 0.0001 & 0.0000 \\
\hline & $\ldots$ & $\ldots$ & $\ldots$ & $\ldots$ & $\ldots$ & $\ldots$ & $\ldots$ \\
\hline Week 66 & 0.0000 & 0.0000 & 0.0000 & 0.2758 & 0.7227 & 0.0015 & 0.0000 \\
\hline & $\ldots$ & $\ldots$ & $\ldots$ & $\ldots$ & $\ldots$ & $\ldots$ & $\ldots$ \\
\hline
\end{tabular}

Tab. 1. Selected input data for the simulation of life cycle assessment.

These two KPIs were collected from the outputs of the simulation models and compared, as shown in Figures 5 and 6. The impact of the relationships between the two KPIs can be used to monitor and forecast future production activities. It can deal with profit and cost forecasts based on production cycles of layer hens to support longterm $\mathrm{P} \& \mathrm{~S}$ of new production life cycles. The data analysis procedure proposed in this study can provide much more accurate insight, leading to greater sales and profits in the product market and poultry business.

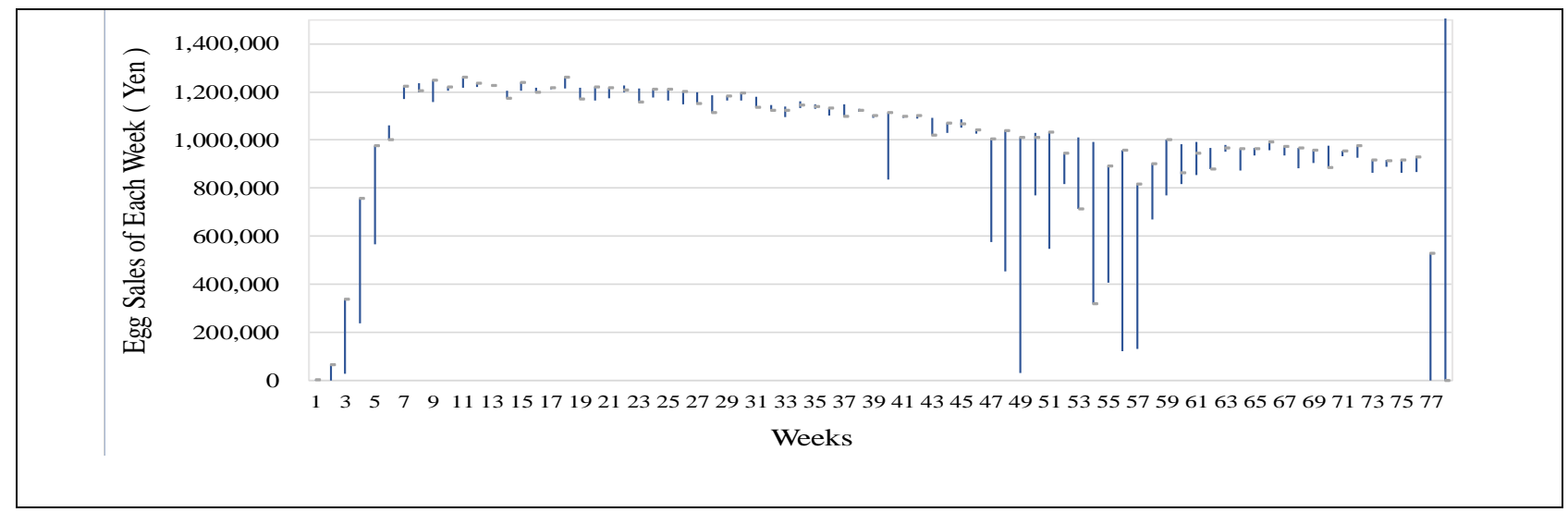

Fig. 5. Egg sales for each week based on a life cycle basis.

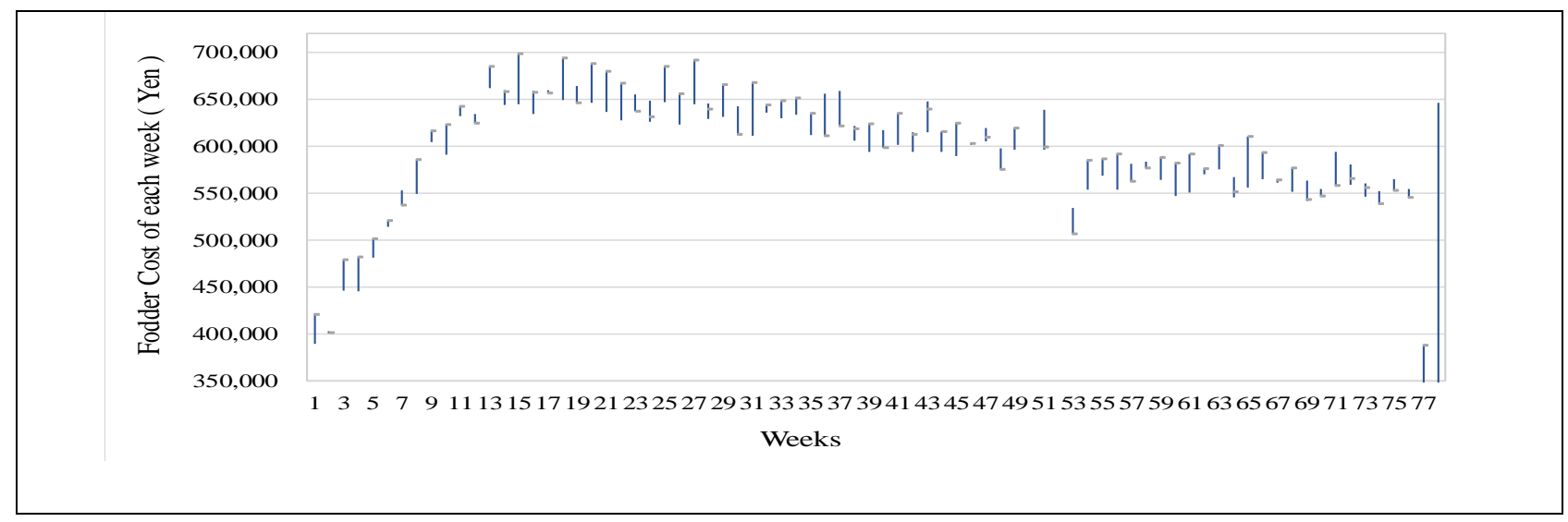

Fig. 6. Fodder costs for each week based on a life cycle basis. 


\section{Conclusion}

In this study, machine learning and simulation are used as associative forecasting methods for LCA of poultry production activities. The procedure of data-driven LCA presented covers production cycle range of layer hens, starting from laying period. Two KPIs are designed to provide additional aid in better decision-making regarding production-level $\mathrm{P} \& \mathrm{~S}$, sales planning, budgeting, and analysis of various operating plans for each poultry production cycle. As a result, machine learning and simulation technological advancements are powerful and effective in economic dicision making, especially for associative utilization of large volumes of both related economic and operational data. Furthermore, long-term planning and scheduling of new production life cycles can be developed and implemented by utilizing the proposed data analysis approach of this study and updating the latest collected data.

As a future research, the proposed data analysis procedure for long-term production of LCA can be used in comparison of different varieties of poultry considering the performance of each complicated production systems. Based on production cycles of different breeds, the profits and costs impacts of the relationships could be tested to identify various feasible alternatives and determine the best alternative to perform in engineering decision making.

\section{Acknowledgments}

I would like to express my thanks to Mr. Daishi Saito who continues to provide actual business data for this study. A special thanks to Mr. David T. Sturrock from Simio LLC for his advice about simulation modeling and scheduling application.

This research is supported by Grants-in-Aid of the Japan Society for the Promotion of Science (JSPS) for Fostering Joint International Research(A) (Grant Number: 17KK0078).

\section{References}

Buchmeister, B.; Palcic, I. \& Ojstersek, R. (2019). Artificial Intelligence in Manufacturing Companies and Broader: An Overview, Chapter 07 in DAAAM International Scientific Book 2019, pp. 81-98, B. Katalinic (Ed.), Published by DAAAM International, ISBN 978-3-902734-24-2, ISSN 1726-9687, Vienna, Austria. DOI: $10.2507 /$ daaam.scibook.2019.07

Gaku, R.; Sturrock, D. T. \& Takakuwa, S. (2020). Simulation and the Fourth Industrial Revolution, St. Andrew's University Pan-Pacific business review (Japanese edition), Vol. 21, pp. 69-79.

McAuliffe, G. A.; Chapman, D. V. \& Sage C. L. (2016). A Thematic Review of Life Cycle Assessment (LCA) Applied to Pig Production, Environmental Impact Assessment Review, Vol. 56, pp. 12-22.

Pinedo, M. L. (2016). Scheduling: Theory, Algorithms, and Systems, Springer, ISBN 978-3319265780, NewYork, NY.

Sturrock, D. T.; Kelton, W. D. \& Smith, J. S. (2018). Simio and Simulation: Modeling, Analysis, Applications, Simio LLC, Sewickley, PA. 